\title{
Epífitas da floresta seca da Reserva Ecológica Estadual de JACAREPIÁ, SUDESTE dO BRASIL: RELAÇÕES COM A COMUNIDADE ARBÓREA
}

\author{
Talita Fontoura ${ }^{1,2,5}$, Marcia Alexandra Rocca ${ }^{2}$, \\ Ana Cristina Schilling ${ }^{3}$ \& Fernanda Reinert ${ }^{4}$
}

\begin{abstract}
Resumo
(Epífitas da floresta seca da Reserva Ecológica Estadual de Jacarepiá, sudeste do Brasil: relações com a comunidade arbórea) Investigamos a vegetação arbórea e a comunidade epífita da floresta seca para responder às seguintes perguntas: i) como a abundância e riqueza de epífitas ocorrem sobre os indivíduos das espécies arbóreas? ii) a abundância de forófitos depende do número de indivíduos das espécies arbóreas? iii) a abundância e riqueza de epífitas dependem do número e tamanho dos forófitos? iv) espécies arbóreas são selecionadas por espécies epifíticas? Nesta floresta, as espécies arbóreas mais abundantes é que hospedam a maioria das epífitas. Quatorze espécies arbóreas foram especialmente propensas a apresentar muitos grupos epifíticos e nove propícias a possuir várias espécies de epífitas mas não em alta abundância. O número de indivíduos arbóreos foi um bom parâmetro para estimar a abundância de forófitos e seu número foi considerado um bom parâmetro para estimar a riqueza de epífitas a ocorrerem nesta floresta seca. Quatro espécies arbóreas foram especialmente preferidas pelas duas espécies epífitas de maior abundância e frequiência na área, onde ocorreram com alta abundância. Entretanto, não houve seletividade de nenhuma espécie arbórea por epífitas raras que ocorreram na área.

Palavras-chave: mata atlântica, restinga, comensalismo, redes de interação.
\end{abstract}

\section{Abstract}

(Epiphytes from the dry forest of the Jacarepiá State Ecological Reserve, southeastern Brazil: interactions with the arboreal community) We investigated the arboreal vegetation and epiphytic community of a 'restinga' dry forest to answer the following questions: i) how does epiphyte abundance and richness occur on arboreal species? ii) does phorophyte abundance depend on the abundance of tree species? iii) does epiphyte abundance and richness depend on the size and abundance of phorophytes? iv) are arboreal species selected by epiphyte species? The most abundant arboreal species host most of the epiphytes. Fourteen arboreal species were especially prone to hosting many epiphyte groups and nine arboreal species were especially prone to hosting only high epiphyte richness. The abundance of arboreal species was a good surrogate to predict the number of phorophytes, and the number of phorophytes was a good surrogate to predict epiphyte abundance and epiphyte richness. Four arboreal species were especially preferred by the most abundant epiphyte species. Nevertheless, no rare epiphyte species had high abundance on any tree species.

Key words: Atlantic rainforest, restinga vegetation, commensalism, interaction networks.

\section{INTRODUÇÃO}

O estudo de plantas epífitas tem indicado alguns padrões gerais sobre como esta forma de vida ocupa a comunidade arbórea e como a comunidade arbórea hospeda estas plantas. Por exemplo, a partir de estudos desenvolvidos nas florestas tropicais da América Central (Migenis \& Ackerman 1993; Zotz \& Vollrath
2003) e na floresta atlântica do nordeste do Brasil (Alves 2005), é possível dizer que a maior freqüência de forófitos (árvores vivas que suportam epífitas) ocorre geralmente entre as árvores de grande diâmetro. É provável que árvores só se tornem potenciais forófitos a partir de determinado tamanho, tornando-se poleiros para morcegos e aves (Greenberg 1996; Galindo-

Artigo recebido em 05/2008. Aceito para publicação em 02/2009.

${ }^{1}$ Parte da dissertação de mestrado, desenvolvida na Universidade Federal do Rio de Janeiro, Programa de Pós Graduação em Ecologia.

${ }^{2}$ Universidade Estadual de Santa Cruz, Dep. Ciências Biológicas, Rod. Ilhéus-Itabuna, km16, 45650-000, Ilhéus, BA, Brasil. ${ }^{3}$ Universidade Estadual de Santa Cruz, Dep. Ciências Exatas e Tecnológicas, Rod. Ilhéus-Itabuna, km16, 45650-000, Ilhéus, BA, Brasil

${ }^{4}$ Universidade Federal do Rio de Janeiro, CCS, Dep. Botânica, IB, 21941-970, Rio de Janeiro, RJ, Brasil.

${ }^{5}$ Autor para correspondência: talita_fontoura@uol.com.br 
González et al. 2000), que são potenciais dispersores de sementes de epífitas ou por se tornarem alvos mais fáceis para serem atingidos por sementes (Bennett 1987).

Plantas epífitas nem sempre ocorrem em maior abundância nas árvores de maior diâmetro, pois alguns trabalhos relatam correlação entre a abundância de epífitas e o diâmetro das árvores (Ingram \& Nadkarni 1993; Moran et al. 2003; Bennet 1987) e outros reportam a ausência de correlação (Zotz \& Vollrath 2003; Alves 2005). Alguns autores afirmam que diferentes fatores são responsáveis pelo não acúmulo de epífitas sobre as maiores árvores do terreno como, por exemplo, a queda de ramos (Benzing 1990) ou desalojamento provocado por vertebrados que ocupam o dossel (Perry 1978).

Análises mais detalhadas sobre a especificidade entre espécies epífitas e arbóreas, no entanto, ainda carecem de melhor entendimento acerca dos possíveis padrões desta interação de comensalismo. Alguns autores relatam a ausência de especificidade entre estas formas de vida (Benzing 1990, Hietz \& Hietz-Seifert 1995) e outros relatam que algumas comunidades epífitas podem ser identificadas devido à presença de algumas espécies arbóreas ocorrentes em uma área (Ter Steege \& Cornelissen 1989; Hietz \& Hietz-Seifert 1995; Carlsen 2000). Embora não respondendo definitivamente a esta questão, estudos experimentais com Tillandsia (Bromeliaceae) levaram Callaway et al. (2002) a sugerirem que quanto mais xérico for o ambiente, maior será a importância das características dos hospedeiros, tornando a interação entre epífitas e hospedeiras mais espécie-específica. Esta hipótese também foi citada em trabalhos desenvolvidos com orquídeas epífitas na mata de restinga subtropical na região sul do Brasil (Waechter 1980) sendo possível que esta maior especificidade ocorra para epífitas em geral.

Seguindo esta hipótese, especificidades poderiam ser detectadas no caso de algumas espécies arbóreas apresentarem maior abundância ou riqueza de epífitas em comparação com as demais espécies arbóreas em áreas de baixa umidade. A floresta seca da Reserva Ecológica Estadual de Jacarepiá (REEJ) seria um local ideal para investigar a ocorrência de tal especificidade, pois apesar de possuir sua vegetação sob um regime de baixa pluviosidade anual $\left(<1000 \mathrm{~mm}\right.$ ano $\left.{ }^{-1}\right)$, diferentes famílias epífitas e árvores com altas densidades desta forma de vida são observadas na área.

Este trabalho objetiva investigar a vegetação arbórea e caracterizar a flora epífita de angiospermas da floresta seca da REEJ para responder às seguintes perguntas: i) como a abundância e riqueza de epífitas ocorrem sobre os indivíduos das espécies arbóreas? ii) a abundância de forófitos depende do número de indivíduos das espécies arbóreas? iii) a abundância e riqueza de epífitas dependem do número e tamanho dos forófitos? iv) espécies arbóreas são selecionadas por espécies epifíticas?

\section{Materiale Métodos Área de Estudos}

A floresta seca de Jacarepiá está inserida na Reserva Ecológica Estadual de Jacarepiá (REEJ), município de Saquarema, a $107 \mathrm{~km}$ a leste da cidade do Rio de Janeiro (22 $47^{\circ}-22^{\circ}$ $57^{\prime}$ 'S; $42^{\circ} 20^{\prime}-42^{\circ} 43^{\prime} \mathrm{W}$ ). A área total da REEJ é $12,5 \mathrm{~km}^{2}$, a pluviosidade anual é de $987 \mathrm{~mm}$ $a^{-1}$ (Sá 2002) e a vegetação predominante é um mosaico de comunidades vegetais denominada restinga. Seis comunidades foram descritas (Sá 1992): halófila, psamófila reptante, "scrub" de Palmae, brejo herbáceo e floresta seca.

A floresta seca se situa sobre a planície costeira arenosa, em uma localização intermediária entre a lagoa de Jacarepiá e o brejo herbáceo, sendo paralela ao oceano (Cirne et al. 2003; Geßler et al. 2005). O solo é arenoso, coberto por uma fina camada de serrapilheira e possui baixa retenção de água após a chuva (Sá 1992). O dossel apresenta árvores que podem atingir $20 \mathrm{~m}$ de altura e as 
espécies arbóreas mais freqüentes são Algernonia obovata, Pterocarpus rohrii, Pseudopiptadenia contorta, Guapira opposita e Alseis involuta (Sá 1992).

\section{Amostragem}

A lista de espécies epífitas ocorrentes na floresta seca foi baseada em coletas de campo efetuadas durante cinco anos e em espécimes depositados no herbário do Instituto de Pesquisas Jardim Botânico do Rio de Janeiro (RB).

Os dados sobre as epífitas, forófitos e árvores foram baseados no método de quadrantes (Cottam \& Curtis 1956) no único fragmento de floresta da região (veja Sá \& Araújo 2009, neste volume).

Para as epífitas presentes nos forófitos, foram registrados os dados de abundância de cada espécie. A abundância de epífitas foi baseada no número de grupos formados, sem considerar o número de rametos constituintes (e.g., número de bulbos de orquídeas ou número de rosetas de bromélias).

\section{Análise de dados}

A estrutura da comunidade arbórea foi caracterizada através da quantidade de indivíduos arbóreos por espécie, pela distribuição de frequiência de indivíduos por espécie e pelo cálculo da área equivalente dos indivíduos amostrados (veja Sá \& Araújo 2009, neste volume).

A abundância e riqueza de epífitas sobre a comunidade arbórea foram investigadas através do cálculo de razões entre epífitas e forófitos, dividindo-se: a) a abundância de epífitas pela abundância de forófitos na espécie arbórea $x$; e b) a riqueza de epífitas pela abundância de forófitos na espécie arbórea $x$. Razões de abundância ou de riqueza de epífitas $\geq 2$ foram consideradas como "altas", devido à ausência de padrões pré-estabelecidos para estes parâmetros. Este valor foi adotado a partir da observação dos dados que indicaram que cerca de $72 \%$ das razões de abundância e riqueza possuíam valores menores que 2,0.

As possíveis dependências entre a abundância de forófitos, a abundância de epífitas e a riqueza de epífitas foram investigadas através da utilização de análises de regressão, buscando-se verificar o modelo mais adequado para explicar a relação entre as seguintes variáveis: a) abundância de forófitos e abundância de indivíduos arbóreos na espécie $x$; b) abundância de epífitas e abundância de forófitos na espécie $x$; c) abundância de epífitas e tamanho dos forófitos (representado pela área basal) na espécie $x$; d) riqueza de epífitas e abundância de forófitos na espécie $x$; e) riqueza de epífitas e área basal dos forófitos na espécie $x$.

Foram utilizadas as 44 espécies de forófitos (F) e as 20 espécies de epífitas (E) para montar duas matrizes. A matriz qualitativa foi baseada na presença ou ausência de interação, e a matriz quantitativa foi baseada na intensidade ou número de interações (neste caso, abundância de grupos epifíticos) para visualização dos padrões de configuração (Bascompte et al. 2003; Lewinsohn et al. 2006). Esta análise é freqüentemente utilizada para investigar redes de interações mutualísticas e pressupõe algum grau de coevolução entre os organismos envolvidos (Bascompte et al. 2003; Lewinsohn et al. 2006). No presente trabalho, é esperado que este tipo de abordagem possa gerar hipóteses não evolutivas sobre as possíveis razões da associação entre epífitas e espécies de forófitos e que as possíveis preferências entre epífitas e forófitos possam ser detectadas. Os descritores de rede ( sensu Olesen \& Jordano 2002) utilizados foram: tamanho de rede, número total de interações da rede, conectividade, número médio de interações por forófito e número médio de interações por epífita.

Neste trabalho, foram consideradas raras as epífitas que ocorreram sobre uma ou, no máximo, duas espécies de forófito. É importante notar que o conceito de raridade possui um alto grau de arbitrariedade e está relacionado à "baixa abundância" ou "baixa frequiência" (Gaston 1994). Por outro lado, as "altas abundâncias" denotam epífitas que ocorreram com cinco ou mais grupos sobre as espécies de forófitos. Dessa forma, espera-se que estes padrões de ocorrência possam indicar quais espécies de 
forófitos são mais propensas ao estabelecimento das epífitas.

\section{Resultados}

Trinta e quatro espécies epífitas foram coletadas na floresta seca sendo representadas principalmente por Orchidaceae $(35,3 \%)$, Bromeliaceae $(32,4 \%)$ e Cactaceae $(23,5 \%)$. Do total de espécies epífitas da floresta seca, $61,8 \%(\mathrm{~S}=21)$ ocorreu nas árvores dos pontos quadrantes da REEJ (Tab. 1).

As árvores amostradas nos pontos quadrantes perfizeram uma área equivalente a 0,5 ha. Foram representadas por 114 espécies e metade $(50,9 \%)$ apresentou abundância variando de um a três indivíduos (Fig. 1). Epífitas ocorreram em 110 forófitos, distribuídos em 44 espécies (Tab. 2) totalizando 38,6\% das espécies arbóreas amostradas.

A abundância de forófitos por espécie arbórea tendeu a diminuir à medida que a abundância das árvores diminuiu (Tab. 2). Consequentemente, a percentagem de forófitos tendeu a aumentar nas espécies arbóreas com reduzido número de indivíduos (Tab. 2).

No total, 14 espécies de forófitos apresentaram razão de abundância de epífitas por forófito maior ou igual a dois grupos (Tab. 2). A razão entre abundância de epífitas e de forófitos foi variável. Os 11 indivíduos de Algernonia obovata hospedaram 15 grupos de epífitas, mas outros 11 indivíduos de Alseis involuta hospedaram 22 grupos resultando em uma razão de dois grupos de epífitas por forófito.

Apenas cinco espécies de forófitos apresentaram razão de riqueza de epífita por forófito maior ou igual a dois (Tab. 2). Todas as espécies de forófito que apresentaram alta razão de riqueza também apresentaram alta razão na abundância de epífitas (Tab. 2) e as demais nove espécies de forófito apresentaram alta razão somente na abundância de epífitas por forófito.

Espécies arbóreas mais abundantes tenderam a ter mais forófitos entre seus indivíduos e a regressão linear foi o modelo que melhor explicou a relação entre as variáveis $\left(R^{2}=0,7\right.$, $\mathrm{P}<0,001$; Fig. 2).
Espécies de forófitos mais abundantes tenderam a apresentar maior abundância e maior riqueza de epífitas (Fig. 3a,b). A regressão linear foi o modelo que melhor explicou a relação entre a abundância de forófitos e de epífitas $\left(\mathrm{R}^{2}=0,7, \mathrm{P}<0,001\right)$ e a regressão geométrica foi o modelo que melhor explicou a relação entre a abundância de forófitos e a riqueza de epífitas $\left(\mathrm{R}^{2}=0,69, \mathrm{P}<0,001\right)$.

Espécies forofíticas com grande área basal não apresentaram relação com o aumento da riqueza ou da abundância de epífitas e todos os modelos testados apresentaram coeficientes de determinação menores que $36 \%$.

Foram registradas 108 interações, formando uma rede assimétrica com um número maior de espécies de forófitos do que de epífitas havendo um número maior de interações por epífitas do que por forófitos (Tab. 3).

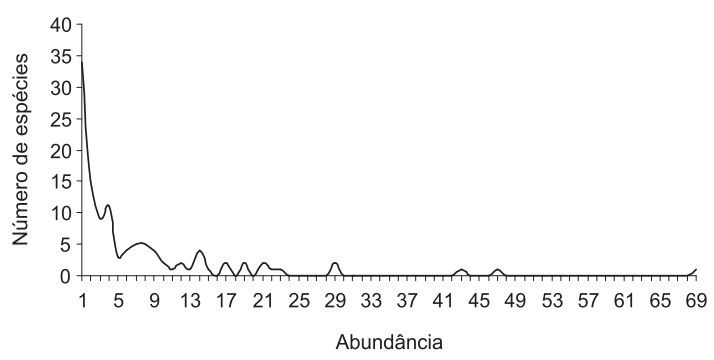

Figura 1-Distribuição de frequiência de indivíduos por espécie arbórea na floresta seca de Jacarepiá, sudeste do Brasil.

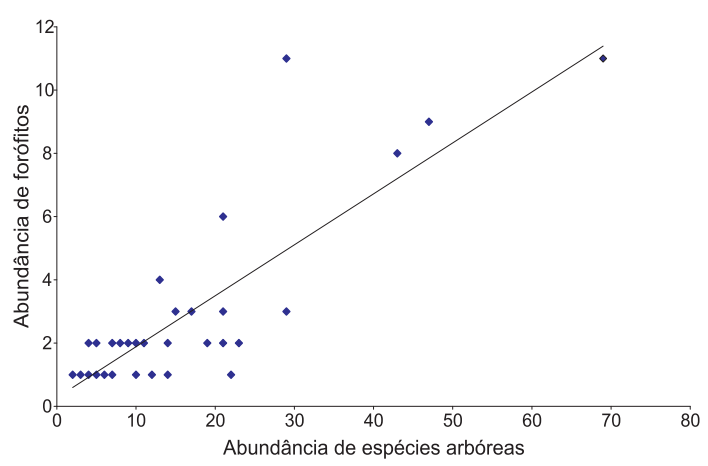

Figura 2 - Regressão linear entre abundância de espécies arbóreas e forofíticas na floresta seca de Jacarepiá, sudeste do Brasil. $Y^{\prime}=0,273+0,161 X ; R^{2}=0,7 ; P<0,001$. 
Tabela 1 - Epífitas coletadas na área da reserva (FS) e nas árvores amostradas pelo método de pontos quadrantes (PT) da floresta seca de Jacarepiá, sudeste do Brasil. Espécies não coletadas pelas autoras $(*)$.

\begin{tabular}{|c|c|c|}
\hline Famílias & Espécies & Local de coleta \\
\hline ARACEAE & Anthurium coriaceum G.Don & PT \\
\hline BROMELIACEAE & $\begin{array}{l}\text { Aechmea fasciata (Lindl.) Baker } \\
\text { Aechmea floribunda Mart. ex Schult. F. } \\
\text { Aechmea nudicaulis } \text { (L.) Griseb. } \\
\text { Aechmea sphaerocephala Baker } \\
\text { Billbergia amoena (Lodd.) Lindl. } \\
\text { Billbergia pyramidalis } \text { (Sims) Lindl. } \\
\text { Neoregelia eltoniana Weber } \\
\text { Tillandsia stricta } \text { Sol. ex Sims } \\
\text { Tillandsia usneoides }(\text { L.) L. } \\
\text { Vriesea procera } \text { (Mart. ex Schult.f.) Wittm. } \\
\text { Vriesea sucrei L.B.Sm. \& Read }\end{array}$ & $\begin{array}{l}\text { PT } \\
\text { PT } \\
\text { FS } \\
\text { PT } \\
\text { PT } \\
\text { PT } \\
\text { PT } \\
\text { PT } \\
\text { FS } \\
\text { PT } \\
\text { FS }\end{array}$ \\
\hline CACTACEAE & $\begin{array}{l}\text { Epiphyllum phyllanthus (L.) Haw. var. phyllanthus* } \\
\text { Hylocereus undatus (Haw.) Britton \& Rose } \\
\text { Lepismium cruciforme(Vell.) Miq. } \\
\text { Rhipsalis baccifera (J.S. Muell.) Stearn } \\
\text { Rhipsalis crispata } \text { (Haw.) Pfeiff. } \\
\text { Rhipsalis oblonga Loefgr. * } \\
\text { Rhipsalis pachyptera } \text { Pfeiff. * } \\
\text { Selenicereus setaceus } \text { Salm-Dyck A. Berger } \text { ex Werderm.* }\end{array}$ & $\begin{array}{l}\text { FS } \\
\text { FS } \\
\text { PT } \\
\text { PT } \\
\text { PT } \\
\text { FS } \\
\text { * FS } \\
\text { FS }\end{array}$ \\
\hline GESNERIACEAE & Codonanthe gracilis (Mart.) Hanst. & PT \\
\hline ORCHIDACEAE & $\begin{array}{l}\text { Brassavola } \text { cf. flagellaris Barb. Rodr. * } \\
\text { Campylocentrum robustum Cogn. } \\
\text { Cattleya guttata Lindl. } \\
\text { Cyrtopodium sp. } \\
\text { Notylia sp.* } \\
\text { Oeceocladesmaculata (Lindl.) Lindl. } \\
\text { Oncidium ciliatum Lindl. } \\
\text { Oncidium leminghei E.Morren } \\
\text { Pleurothallis saundersiana Rchb. f. } \\
\text { Pleurothallis sp.* } \\
\text { Polystachya } \text { sp. } 1 * \\
\text { Trichocentrum fuscum Lindl. }\end{array}$ & $\begin{array}{l}\text { FS } \\
\text { PT } \\
\text { PT } \\
\text { FS } \\
\text { FS } \\
\text { PT } \\
\text { PT } \\
\text { FS } \\
\text { PT } \\
\text { FS } \\
\text { PT } \\
\text { PT }\end{array}$ \\
\hline PIPERACEAE & Peperomia corcovadensis Gardner & PT \\
\hline
\end{tabular}

A rede formada é do tipo aninhada, na qual as espécies epífitas com menor número de interações interagem com os forófitos que possuem maior número de interações e viceversa, criando um grupo central de espécies que interagem entre si (Fig. 4). Dezenove espécies de forófitos apresentaram apenas uma espécie de epífita e 14 espécies de forófito apresentaram duas espécies, totalizando cerca de $75 \%$ de espécies com baixa ocorrência de epífitas (Tab. 4). As duas epífitas com maiores frequiências sobre os forófitos foram Aechmea fasciata e Vriesea procera que ocorreram em 20 e 19 forófitos respectivamente (Tab. 4) fazendo parte do grupo central de espécies epífitas da rede de interações. Por outro lado, 
Tabela 2 - Parâmetros observados e calculados de espécies de forófitos na floresta seca de Jacarepiá, sudeste do Brasil. Abundância de indivíduos (Nind), abundância de forófitos (Nfor), percentagem de forófitos (\%for), abundância de epífitas (Nepi), razão entre abundância de epífitas e de forófitos (Nepi/Nfor), riqueza de epífitas (Sepi), razão entre riqueza de epífitas e abundância de forófitos (Sepi/Nfor). Razões $\geq 2$ ressaltadas em negrito.

\begin{tabular}{|c|c|c|c|c|c|c|c|}
\hline Espécie de forófito & Nind & Nfor & $\%$ for & Nepi & Nepi/Nfor & Sepi & Sepi/Nfor \\
\hline 1 Algernonia obovata Müll. Arg. & 69 & 11 & 15,9 & 15 & 1,4 & 8 & 0,7 \\
\hline 2 Pterocarpus rohri Vahl & 47 & 9 & 19,1 & 12 & 1,3 & 5 & 0,6 \\
\hline 3 Pseudopiptadenia contorta (DC.) GP. Lewis \& M.P. Lima & 43 & 8 & 18,6 & 9 & 1,1 & 5 & 0,6 \\
\hline 4 Alseis involuta $\mathrm{K}$. Schum. & 29 & 11 & 37,9 & 22 & 2,0 & 9 & 0,7 \\
\hline 5 Guapira opposita (Vell.) Reitz & 29 & 3 & 10,3 & 9 & 3,0 & 6 & 2,0 \\
\hline 6 Galipea sp. & 23 & 2 & 8,7 & 4 & 2,0 & 2 & 1,0 \\
\hline 7 Brosimum guianense (Aubl.) Huber & 22 & 1 & 4,5 & 1 & 1,0 & 1 & 1,0 \\
\hline 8 Aspidosperma parvifolium A. DC. & 21 & 2 & 9,5 & 6 & 3,0 & 2 & 1,0 \\
\hline 9 Pouteria grandiflora (A. DC.) Baehni & 21 & 3 & 14,3 & 3 & 1,0 & 3 & 1,0 \\
\hline 10 Simaba cuneata A. St.-Hil. \& Tul. & 21 & 6 & 28,6 & 6 & 1,0 & 4 & 0,7 \\
\hline 11 Astronium graveolens Jacq. & 19 & 2 & 10,5 & 2 & 1,0 & 1 & 0,5 \\
\hline 12 Lauraceae sp.1 & 19 & 2 & 10,5 & 2 & 1,0 & 2 & 1,0 \\
\hline 13 Duguetia rhizantha (Eichler) Huber & 17 & 3 & 17,6 & 3 & 1,0 & 3 & 1,3 \\
\hline 14 Indet. sp. 2 & 15 & 3 & 20,0 & 11 & 3,7 & 5 & 1,7 \\
\hline 15 Annonaceae indet. & 14 & 1 & 7,1 & 3 & 3,0 & 2 & 2,0 \\
\hline 16 Eriotheca pentaphylla (Vell.) A. Robyns. & 14 & 1 & 7,1 & 1 & 1,0 & 1 & 1,0 \\
\hline 17 Guettarda viburnoides Cham. \& Schltdl. & 14 & 2 & 14,3 & 2 & 1,0 & 2 & 1,0 \\
\hline 18 Chrysophyllum lucentifolium Cronquist & 13 & 4 & 30,8 & 5 & 1,3 & 2 & 0,5 \\
\hline 19 Eugenia tocaiana O. Berg & 12 & 1 & 8,3 & 2 & 2,0 & 1 & 1,0 \\
\hline 20 Couepia schottii Fritsch & 11 & 2 & 18,2 & 9 & 4,5 & 6 & 3,0 \\
\hline 21 Erythroxylum pulchrum A. St.-Hil. & 10 & 2 & 20,0 & 11 & 5,5 & 7 & 3,5 \\
\hline
\end{tabular}




\begin{tabular}{|c|c|c|c|c|c|c|c|}
\hline Espécie de forófito & Nind & Nfor & $\%$ for & Nepi & Nepi/Nfor & Sepi & Sepi/Nfor \\
\hline 22 Inga fagifolia (L.) Willd. ex Benth. & 10 & 1 & 10,0 & 1 & 1,0 & 1 & 1,0 \\
\hline 23 Allophylus puberulus Radlk. & 9 & 2 & 22,2 & 2 & 1,0 & 2 & 1,0 \\
\hline 24 Phyllanthus aff. riedelianus Müll. Arg. & 9 & 2 & 22,2 & 3 & 1,5 & 2 & 1,0 \\
\hline 25 Indet. sp. 1 & 8 & 2 & 25,0 & 2 & 1,0 & 2 & 1,0 \\
\hline 26 Carpotroche brasiliensis (Raddi) A. Gray & 7 & 1 & 14,3 & 1 & 1,0 & 1 & 1,0 \\
\hline 27 Cathedra rubricaulis Miers & 7 & 2 & 28,6 & 5 & 2,5 & 2 & 1,0 \\
\hline 28 Chrysophyllum januariense Eichler & 7 & 2 & 28,6 & 2 & 1,0 & 2 & 1,0 \\
\hline 29 Exostyles venusta Schott ex Spreng. & 7 & 1 & 14,3 & 1 & 1,0 & 1 & 1,0 \\
\hline 30 Rheedia brasiliensis (Mart.) Planch. \& Triana & 7 & 2 & 28,6 & 2 & 1,0 & 2 & 1,0 \\
\hline 31 Coutarea hexandra (Jacq.) K.Schum. & 6 & 1 & 16,7 & 1 & 1,0 & 1 & 1,0 \\
\hline 32 Ocotea divaricata (Nees) Mez & 6 & 1 & 16,7 & 1 & 1,0 & 1 & 1,0 \\
\hline 33 Vitex rufescens A. Juss. & 6 & 1 & 16,7 & 1 & 1,0 & 1 & 1,0 \\
\hline 34 Buchenavia aff. Kleinii Exell & 5 & 1 & 20,0 & 3 & 3,0 & 1 & 1,0 \\
\hline 35 Pavonia alnifolia A. St.-Hil. & 5 & 1 & 20,0 & 1 & 1,0 & 1 & 1,0 \\
\hline 36 Poecilanthe falcata (Vell.) Heringer & 5 & 2 & 40,0 & 2 & 1,0 & 1 & 0,5 \\
\hline 37 Indet. sp.8 & 4 & 1 & 25,0 & 2 & 2,0 & 1 & 1,0 \\
\hline 38 Zollernia glabra (Spreng.) Yakolev & 4 & 2 & 50,0 & 3 & 1,5 & 2 & 1,0 \\
\hline 39 Andira legalis (Vell.) Toledo & 3 & 1 & 33,3 & 1 & 1,0 & 1 & 1,0 \\
\hline 40 Casearia $\mathrm{sp} .1$ & 2 & 1 & 50,0 & 1 & 1,0 & 1 & 1,0 \\
\hline 41 Inga maritima Benth. & 2 & 1 & 50,0 & 1 & 1,0 & 1 & 1,0 \\
\hline 42 Pradosia lactescens (Vell.) Radlk. & 2 & 1 & 50,0 & 1 & 1,0 & 1 & 1,0 \\
\hline 43 Sapotaceae sp. 1 & 2 & 1 & 50,0 & 2 & 2,0 & 2 & 2,0 \\
\hline 44 Sapotaceae sp.2 & 2 & 1 & 50,0 & 2 & 2,0 & 1 & 1,0 \\
\hline
\end{tabular}


Tabela 3 - Descritores de redes de interações da matriz de 44 espécies de forófitos (F) e 20 espécies de epífitas (E) na floresta seca de Jacarepiá, sudeste do Brasil. Características matemáticas de matrizes de tamanho 44 X 20 e da matriz estudada de forófitos e epífitas.

\begin{tabular}{lcc}
\hline Descritor $^{1}$ & $\begin{array}{c}\text { Matriz } \\
\text { 44 X 20 }\end{array}$ & $\begin{array}{c}\text { Forófitos } \\
\text { X Epífitas }\end{array}$ \\
\hline Tamanho de rede $\left(\mathrm{M}=\mathrm{F}^{*} \mathrm{E}\right)$ & 880 & - \\
Número total de interações da rede (I) & - & 108 \\
Conectividade $(\mathrm{C}=100 * \mathrm{I} / \mathrm{M})$ & - & 12,3 \\
Número médio de interações por forófito $(\mathrm{Ln}=\mathrm{I} / \mathrm{F})$ & 2,5 & $2,5 \pm 2,07$ \\
Número médio de interações por epífita $(\mathrm{Lm}=\mathrm{I} / \mathrm{E})$ & 5,4 & $5,4 \pm 5,34$ \\
\hline
\end{tabular}

${ }^{1}$ segundo Olesen \& Jordano (2002)

seis epífitas (30\% do total) ocorreram sobre uma ou duas espécies de forófitos (Tab. 4).

A. fasciata ocorreu em alta abundância sobre Alseis involuta, Indet. sp. 2 e Chrysophyllum lucentifolium e $V$. procera ocorreu em alta abundância sobre Algernonia obovata (Tab. 4). Nenhuma das epífitas com baixa frequiência possuiu alta abundância sobre os forófitos (Tab. 4).

\section{Discussão}

A preponderância de epífitas nas famílias Orchidaceae e Bromeliaceae na mata seca de Jacarepiá corrobora o padrão proposto por Gentry \& Dodson (1987), que assinalaram a dominância destas famílias botânicas em locais de baixa umidade ou que passem por algum rigor climático. Esta mesma preponderância foi registrada em outros levantamentos de epífitas ao longo da floresta atlântica do sul (Waechter 1998; Breier 1999; Kersten \& Silva 2001; Gonçalves \& Waechter 2002; Kersten \& Silva 2002; Gonçalves \& Waechter 2003; Borgo \& Silva 2003) e do sudeste do Brasil (Fontoura et al. 1997; Breier 2005). Entretanto, a porcentagem semelhante entre estas duas famílias de plantas não ocorreu em nenhum dos levantamentos das florestas do sul do Brasil que, via de regra, possuem maior percentagem de orquídeas. As percentagens semelhantes entre Orchidaceae e Bromeliaceae aqui apresentadas e as investigações em quatro localidades da floresta atlântica no estado de São Paulo (sudeste do Brasil) no gradiente litoral-interior (Breier 2005) sugerem que ambientes mais secos afetam diferentemente as principais famílias de epífitas. Nas localidades do estado de São Paulo os índices de pluviosidade variavam de 2027 a $1320 \mathrm{~mm}$ $\mathrm{ano}^{-1}$ e revelaram a ocorrência de seis espécies
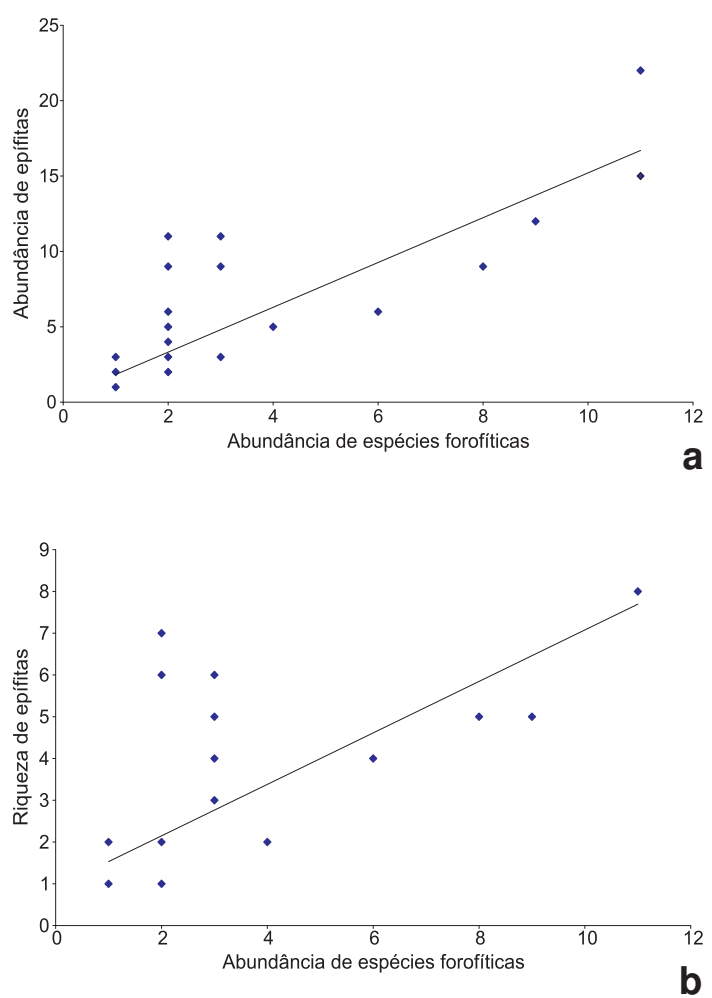

Figura 3 - Regressões entre abundância de espécies forofíticas, abundância e riqueza de epífitas na floresta seca de Jacarepiá, sudeste do Brasil. Em (a) modelo de regressão linear $\mathrm{Y}^{\prime}=0,354+1,486 \mathrm{X} ; \mathrm{R}^{2}=0,71, \mathrm{P}<$ 0,001. Em (b) modelo de regressão geométrica $Y^{\prime}=1,38$ * $\mathrm{X}^{1,058} ; \mathrm{R}^{2}=0,69, \mathrm{P}<0,001$. 
Tabela 4 - Rede de interações quantitativa (abundância de interações) entre as 44 espécies de forófitos e as 20 espécies de epífitas na floresta seca de Jacarepiá, sudeste do Brasil.

\begin{tabular}{|c|c|c|c|c|c|c|c|c|c|c|c|c|c|c|c|c|c|c|c|c|c|}
\hline & 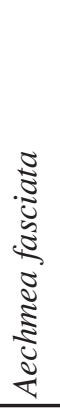 & 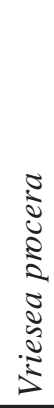 & 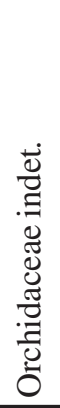 & 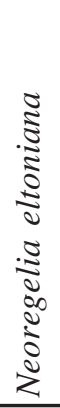 & 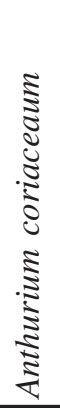 & 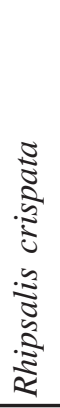 & $\begin{array}{c}0 \\
0 \\
\vdots \\
0 \\
0 \\
0 \\
0 \\
0 \\
0 \\
\vdots \\
0 \\
0 \\
0 \\
\mathbb{2}\end{array}$ & 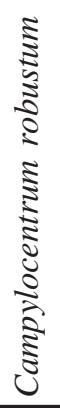 & 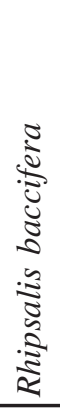 & 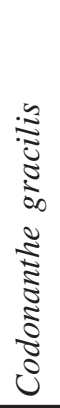 & 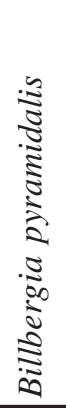 & 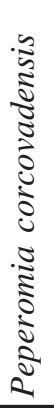 & 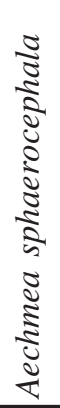 & 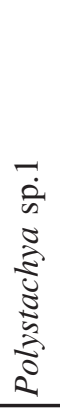 & 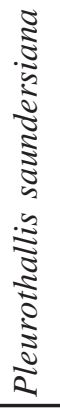 & 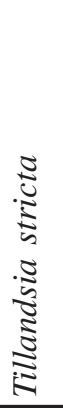 & 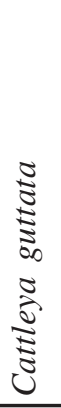 & 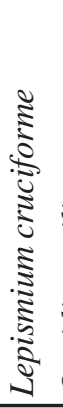 & 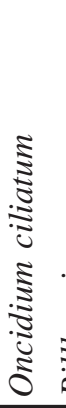 & 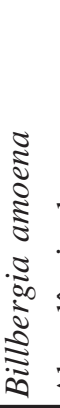 & 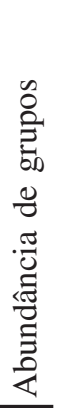 \\
\hline Alseis involuta & 11 & 3 & 1 & 0 & 0 & 1 & 0 & 0 & 1 & 1 & 0 & 2 & 0 & 1 & 1 & 0 & 0 & 0 & 0 & 0 & 22 \\
\hline Algernonia obovata & 1 & 6 & 0 & 1 & 2 & 1 & 0 & 1 & 0 & 1 & 0 & 0 & 0 & 0 & 1 & 0 & 0 & 0 & 0 & 0 & 14 \\
\hline Pterocarpus rohri & 3 & 3 & 3 & 0 & 0 & 0 & 0 & 2 & 0 & 0 & 0 & 0 & 0 & 0 & 0 & 1 & 0 & 0 & 0 & 0 & 12 \\
\hline Erythroxylum pulchrum & 1 & 0 & 0 & 2 & 4 & 1 & 0 & 0 & 1 & 0 & 1 & 0 & 0 & 0 & 0 & 0 & 1 & 0 & 0 & 0 & 11 \\
\hline Indet. sp. 2 & 6 & 1 & 2 & 0 & 0 & 0 & 1 & 0 & 0 & 0 & 0 & 0 & 0 & 0 & 1 & 0 & 0 & 0 & 0 & 0 & 11 \\
\hline Couepia schottii & 2 & 3 & 0 & 0 & 1 & 0 & 0 & 0 & 0 & 1 & 0 & 0 & 0 & 0 & 0 & 1 & 0 & 0 & 0 & 1 & 9 \\
\hline Guapira opposita & 1 & 0 & 0 & 0 & 0 & 2 & 1 & 0 & 2 & 0 & 2 & 0 & 1 & 0 & 0 & 0 & 0 & 0 & 0 & 0 & 9 \\
\hline Pseudopiptadenia contorta & 3 & 1 & 3 & 0 & 0 & 0 & 1 & 0 & 1 & 0 & 0 & 0 & 0 & 0 & 0 & 0 & 0 & 0 & 0 & 0 & 9 \\
\hline Simaba cuneata & 2 & 2 & 0 & 0 & 1 & 0 & 0 & 0 & 0 & 0 & 1 & 0 & 0 & 0 & 0 & 0 & 0 & 0 & 0 & 0 & 6 \\
\hline Chrysophyllum lucentifolium & 5 & 0 & 0 & 0 & 0 & 0 & 0 & 0 & 0 & 0 & 0 & 0 & 0 & 1 & 0 & 0 & 0 & 0 & 0 & 0 & 6 \\
\hline Aspidosperma parvifolium & 0 & 1 & 5 & 0 & 0 & 0 & 0 & 0 & 0 & 0 & 0 & 0 & 0 & 0 & 0 & 0 & 0 & 0 & 0 & 0 & 6 \\
\hline Cathedra rubricaulis & 4 & 0 & 0 & 0 & 0 & 0 & 0 & 0 & 0 & 1 & 0 & 0 & 0 & 0 & 0 & 0 & 0 & 0 & 0 & 0 & 5 \\
\hline Galipea sp. & 3 & 0 & 1 & 0 & 0 & 0 & 0 & 0 & 0 & 0 & 0 & 0 & 0 & 0 & 0 & 0 & 0 & 0 & 0 & 0 & 4 \\
\hline Duguetia rhizantha & 1 & 1 & 1 & 0 & 0 & 0 & 0 & 0 & 0 & 0 & 0 & 0 & 0 & 0 & 0 & 0 & 0 & 0 & 0 & 0 & 3 \\
\hline Zollernia glabra & 0 & 2 & 0 & 1 & 0 & 0 & 0 & 0 & 0 & 0 & 0 & 0 & 0 & 0 & 0 & 0 & 0 & 0 & 0 & 0 & 3 \\
\hline Annonaceae indet. & 0 & 1 & 0 & 0 & 0 & 0 & 0 & 0 & 0 & 0 & 0 & 2 & 0 & 0 & 0 & 0 & 0 & 0 & 0 & 0 & 3 \\
\hline Pouteria grandiflora & 1 & 0 & 0 & 0 & 0 & 1 & 0 & 0 & 0 & 0 & 0 & 0 & 0 & 0 & 0 & 0 & 0 & 0 & 1 & 0 & 3 \\
\hline Buchenavia aff. Kleinii & 0 & 0 & 0 & 0 & 0 & 0 & 0 & 3 & 0 & 0 & 0 & 0 & 0 & 0 & 0 & 0 & 0 & 0 & 0 & 0 & 3 \\
\hline Indet. sp.8 & 0 & 0 & 0 & 0 & 0 & 0 & 2 & 0 & 0 & 0 & 0 & 0 & 0 & 0 & 0 & 0 & 0 & 0 & 0 & 0 & 2 \\
\hline Indet. sp.1 & 1 & 0 & 0 & 0 & 0 & 0 & 0 & 0 & 0 & 1 & 0 & 0 & 0 & 0 & 0 & 0 & 0 & 0 & 0 & 0 & 2 \\
\hline Lauraceae sp.1 & 1 & 0 & 0 & 0 & 0 & 0 & 1 & 0 & 0 & 0 & 0 & 0 & 0 & 0 & 0 & 0 & 0 & 0 & 0 & 0 & 2 \\
\hline Rheedia brasiliensis & 1 & 0 & 0 & 0 & 0 & 0 & 1 & 0 & 0 & 0 & 0 & 0 & 0 & 0 & 0 & 0 & 0 & 0 & 0 & 0 & 2 \\
\hline Allophylus puberulus & 1 & 0 & 0 & 0 & 0 & 0 & 0 & 0 & 0 & 0 & 0 & 0 & 0 & 0 & 0 & 0 & 0 & 1 & 0 & 0 & 2 \\
\hline Phyllanthus aff. riedelianus & 1 & 1 & 0 & 0 & 0 & 0 & 0 & 0 & 0 & 0 & 0 & 0 & 0 & 0 & 0 & 0 & 0 & 0 & 0 & 0 & 2 \\
\hline Guettarda viburnoides & 0 & 1 & 0 & 1 & 0 & 0 & 0 & 0 & 0 & 0 & 0 & 0 & 0 & 0 & 0 & 0 & 0 & 0 & 0 & 0 & 2 \\
\hline Eugenia tocaiana & 0 & 0 & 0 & 2 & 0 & 0 & 0 & 0 & 0 & 0 & 0 & 0 & 0 & 0 & 0 & 0 & 0 & 0 & 0 & 0 & 2 \\
\hline Sapotaceae sp.1 & 0 & 0 & 0 & 0 & 1 & 1 & 0 & 0 & 0 & 0 & 0 & 0 & 0 & 0 & 0 & 0 & 0 & 0 & 0 & 0 & 2 \\
\hline Chrysophyllum januariemse & 0 & 0 & 0 & 0 & 0 & 0 & 0 & 0 & 0 & 0 & 0 & 0 & 0 & 1 & 0 & 0 & 1 & 0 & 0 & 0 & 2 \\
\hline Astronium graveolens & 0 & 2 & 0 & 0 & 0 & 0 & 0 & 0 & 0 & 0 & 0 & 0 & 0 & 0 & 0 & 0 & 0 & 0 & 0 & 0 & 2 \\
\hline Sapotaceae sp.2 & 0 & 2 & 0 & 0 & 0 & 0 & 0 & 0 & 0 & 0 & 0 & 0 & 0 & 0 & 0 & 0 & 0 & 0 & 0 & 0 & 2 \\
\hline Pradosia lactescens & 1 & 0 & 0 & 0 & 0 & 0 & 0 & 0 & 0 & 0 & 0 & 0 & 0 & 0 & 0 & 0 & 0 & 0 & 0 & 0 & 1 \\
\hline Carpotroche brasiliensis & 0 & 1 & 0 & 0 & 0 & 0 & 0 & 0 & 0 & 0 & 0 & 0 & 0 & 0 & 0 & 0 & 0 & 0 & 0 & 0 & 1 \\
\hline Casearia sp.1 & 0 & 1 & 0 & 0 & 0 & 0 & 0 & 0 & 0 & 0 & 0 & 0 & 0 & 0 & 0 & 0 & 0 & 0 & 0 & 0 & 1 \\
\hline Inga fagifolia & 0 & 1 & 0 & 0 & 0 & 0 & 0 & 0 & 0 & 0 & 0 & 0 & 0 & 0 & 0 & 0 & 0 & 0 & 0 & 0 & 1 \\
\hline Pavonia alnifolia & 0 & 1 & 0 & 0 & 0 & 0 & 0 & 0 & 0 & 0 & 0 & 0 & 0 & 0 & 0 & 0 & 0 & 0 & 0 & 0 & 1 \\
\hline
\end{tabular}




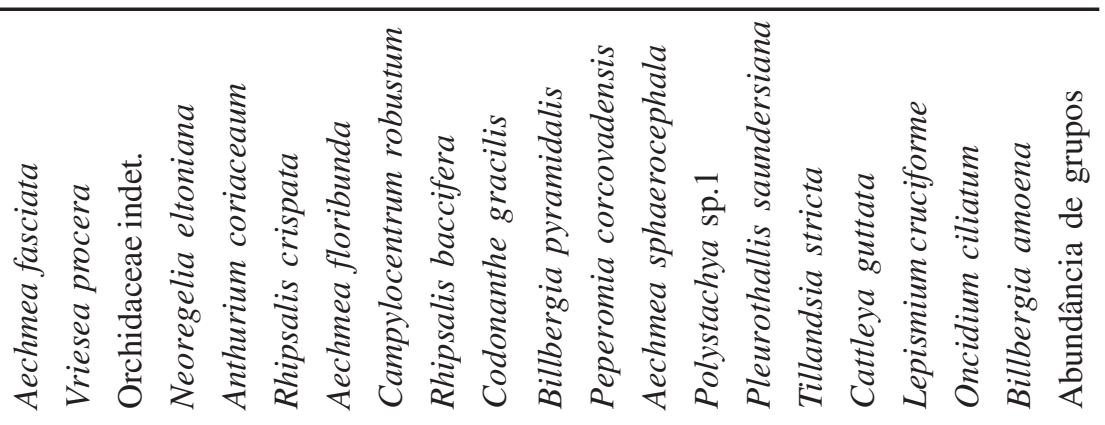

\begin{tabular}{lllllllllllllllllllllll}
\hline Andira legalis & 0 & 0 & 0 & 1 & 0 & 0 & 0 & 0 & 0 & 0 & 0 & 0 & 0 & 0 & 0 & 0 & 0 & 0 & 0 & 0 & $\mathbf{1}$ \\
Exostyles venusta & 0 & 0 & 0 & 1 & 0 & 0 & 0 & 0 & 0 & 0 & 0 & 0 & 0 & 0 & 0 & 0 & 0 & 0 & 0 & 0 & $\mathbf{1}$ \\
Inga maritima & 0 & 0 & 0 & 1 & 0 & 0 & 0 & 0 & 0 & 0 & 0 & 0 & 0 & 0 & 0 & 0 & 0 & 0 & 0 & 0 & $\mathbf{1}$ \\
Ocotea divaricata & 0 & 0 & 0 & 1 & 0 & 0 & 0 & 0 & 0 & 0 & 0 & 0 & 0 & 0 & 0 & 0 & 0 & 0 & 0 & 0 & $\mathbf{1}$ \\
Coutarea hexandra & 0 & 0 & 1 & 0 & 0 & 0 & 0 & 0 & 0 & 0 & 0 & 0 & 0 & 0 & 0 & 0 & 0 & 0 & 0 & 0 & $\mathbf{1}$ \\
Eriotheca pentaphylla & 0 & 0 & 1 & 0 & 0 & 0 & 0 & 0 & 0 & 0 & 0 & 0 & 0 & 0 & 0 & 0 & 0 & 0 & 0 & 0 & $\mathbf{1}$ \\
Poecilathe falcata & 0 & 0 & 0 & 0 & 0 & 0 & 0 & 0 & 0 & 0 & 0 & 0 & 0 & 0 & 0 & 0 & 0 & 1 & 0 & 0 & $\mathbf{1}$ \\
Brosimum guianense & 0 & 0 & 0 & 0 & 0 & 0 & 0 & 0 & 0 & 0 & 0 & 0 & 1 & 0 & 0 & 0 & 0 & 0 & 0 & 0 & $\mathbf{1}$ \\
Vitex rufescens & 0 & 0 & 0 & 0 & 0 & 0 & 0 & 0 & 0 & 0 & 0 & 0 & 1 & 0 & 0 & 0 & 0 & 0 & 0 & 0 & $\mathbf{1}$ \\
\hline & $\mathbf{5 0}$ & $\mathbf{3 4}$ & $\mathbf{1 8}$ & $\mathbf{1 1}$ & $\mathbf{9}$ & $\mathbf{7}$ & $\mathbf{7}$ & $\mathbf{6}$ & $\mathbf{5}$ & $\mathbf{5}$ & $\mathbf{4}$ & $\mathbf{4}$ & $\mathbf{3}$ & $\mathbf{3}$ & $\mathbf{3}$ & $\mathbf{2}$ & $\mathbf{2}$ & $\mathbf{2}$ & $\mathbf{1}$ & $\mathbf{1}$ & \\
\hline
\end{tabular}

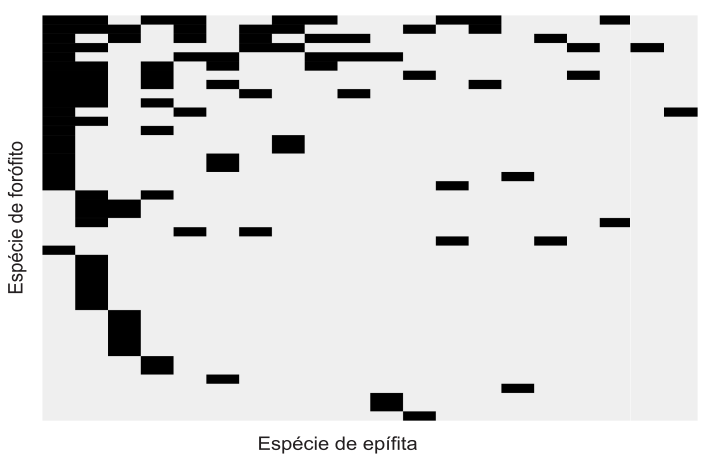

Figura 4 - Rede de interações qualitativa esquemática (presença de interação representada pelo retângulo preto) entre as 44 espécies de forófitos (vertical) e as 20 espécies de epífitas (horizontal) na floresta seca de Jacarepiá, sudeste do Brasil.

de Orchidaceae e sete espécies de Bromeliaceae nas localidades mais secas (1320 e $1401 \mathrm{~mm} \mathrm{ano}^{-1}$ ). Entretanto, as espécies de Orchidaceae representam 6,3\% do total de 95 orquídeas e as Bromeliaceae representam $14,9 \%$ do total de 47 bromélias ocorrentes nas quatro localidades. É possível que locais com baixa pluviosidade ou com períodos de seca demarcada tendam a limitar mais a ocorrência de orquídeas do que a ocorrência de bromélias.
No caso de Jacarepiá, metade das espécies arbóreas é representada por uma a três árvores, mas a maioria dos forófitos ocorreu na outra metade da comunidade arbórea onde os indivíduos são mais abundantes. A utilização desta mesma metodologia em outras regiões seria interessante para verificar se este padrão se modifica ou não em outras áreas de floresta atlântica, a despeito das diferentes composições de espécies arbóreas ao longo do bioma (Scudeller 2002).

Levantamentos fitossociológicos que abordem as comunidades arbórea e epifítica poderiam investigar se a maior quantidade de forófitos ocorre nas espécies arbóreas mais ou menos abundantes. Isso possibilitaria estratégias de manejo das epífitas ocorrentes em diferentes regiões. No caso de Jacarepiá, as cinco primeiras espécies de forófitos com maior número de indivíduos são também as cinco espécies arbóreas de maior abundância na área (Sá \& Araujo 2009). Embora estudos adicionais sejam necessários, é provável que modificações no número de indivíduos destas espécies arbóreas possam, até certo ponto, ter baixo efeito na comunidade epifítica devido ao alto número de 
indivíduos que servem de suporte para a comunidade epífita de Jacarepiá.

Uma vez que inexistem modelos para explicar ocupação de epífitas sobre a comunidade arbórea em florestas secas, as regressões aqui ajustadas poderão ser utilizadas como uma primeira aproximação para outros estudos, lançando hipóteses sobre os padrões de ocupação de epífitas na vegetação arbórea em hábitats secos ou úmidos.

O estudo da comunidade epífita revela padrões em escala regional que demonstraram que a maior riqueza desta forma de vida ocorre em locais mésicos (Gentry \& Dodson 1987) e em locais de altitude média (Cardelús et al. 2006). Entretanto, novos estudos abordando a interação comensalista entre epífitas e a comunidade arbórea em uma escala intermediária de investigação poderia promover teorias ecológicas sobre como espécies epífitas ocupam espécies arbóreas ao longo do terreno e viceversa. Afinal, grande parte da teoria ecológica é baseada em interações de competição (Cox \& Ricklefs 1977; Stewart 1996; Begon et al. 2006), predação (Mooney 2007), mutualismo (Bronstein 1994; Guimarães et al. 2007) e poucos conceitos podem ser traçados sobre o papel do comensalismo na estruturação de comunidades ou nas redes de interações.

As correlações significativas entre número de indivíduos arbóreos e número de forófitos, número de forófitos e abundância de epífitas, e número de forófitos e riqueza de epífitas indicam que, na floresta seca de Jacarepiá, os processos que regem a ocorrência de epífitas e ocupação de forófitos ocorrem em grande parte entre as espécies arbóreas com maior número de indivíduos. Só eventualmente fatores mais específicos devem dirigir a maior ocorrência de epífitas para algumas espécies arbóreas que possuíram uma maior razão de epífitas.

A percentagem de indeterminação dos modelos de regressão linear (ca. de 30\%) pode ser parcialmente atribuída a estas espécies arbóreas que possuíram uma razão maior de epífitas em relação ao número de forófitos, seja na abundância ou na riqueza. Assim, Alseis involuta, Erythroxylum pulchrum, Indet. sp.2, Conepia schottii e Guapira opposita possuíram uma quantidade desproporcional na abundância de epífitas $(n=22,11,11,9$ e 9 grupos respectivamente) e Erythroxylum pulchrum, Couepia schottii, Guapira opposita e indet. sp.2 possuíram uma quantidade desproporcional na quantidade de espécies (7, 6, 6 e 5 espécies respectivamente).

O cálculo das razões entre abundância de forófitos e abundância de epífitas e abundância de forófitos e riqueza de epífitas complementou os resultados das análises de regressão. Além da identificação de quais espécies forofíticas possuem maiores ou menores proporções de epífitas, foi possível verificar quais espécies contribuíram para os resultados das regressões acima citados. Estas duas abordagens permitem também concluir que a ocupação de epífitas depende tanto do número absoluto dos forófitos de algumas espécies arbóreas quanto do número relativo de epífitas sobre outras espécies arbóreas.

A utilização da área basal das espécies arbóreas como possível variável explicativa para a abundância e riqueza de epífitas seguiu aqui o mesmo padrão de outros trabalhos, os quais relataram a ausência de relações significativas entre riqueza ou abundância de epífitas e diâmetro das árvores. Visto que tais resultados ocorreram em diferentes localidades tropicais com diferentes regimes de umidade, então é possível que parâmetros fitossociológicos da vegetação arbórea influenciem mais a ocorrência de forófitos (e de epífitas) do que anteriormente presumido por Benzing (1990). A alta razão de abundância e/ou de riqueza de epífitas sobre os indivíduos de Alseis involuta, Guapira opposita, indet. sp.2, Couepia schottii e Erythroxylum pulchrum indica que processos diferenciados (e.g., tipo de casca do forófito, seleção de hábitat dos dispersores de sementes, inclinação do tronco e ramos) estejam atuando nos indivíduos de algumas espécies promovendo tal maior proporção de epífitas.

Levando em conta que florestas tropicais apresentam grande número de árvores de tamanho pequeno e reduzido número de árvores grandes (Richards 1996) então, o diâmetro (representado pela área basal) foi um parâmetro de menor 
importância para a acumulação de epífitas na floresta seca de Jacarepiá. É provável que, de maneira geral, o reduzido número de indivíduos arbóreos de grande porte não possua características apropriadas para o estabelecimento de vários grupos desta forma de vida. Assim como ocorrente na floresta seca de Jacarepiá, é possível que este padrão ocorra em outras florestas tropicais, resultando na variabilidade de correlações verificada na literatura (Ingram \& Nadkarni 1993; Moran et al. 2003; Bennet 1987; Zotz \& Vollrath 2003; Alves 2005).

A matriz de interações demonstrou que na maioria das vezes as espécies arbóreas apresentam uma ou duas espécies epífitas. Assim, pode-se dizer que o epifitismo seja ocasional entre as espécies arbóreas da floresta seca. Além disso, a baixa abundância da maioria das espécies epífitas indica que a maioria das árvores da floresta seca apresenta condições adversas para que as epífitas se desenvolvam em abundância sobre os forófitos. Assim, as únicas espécies que apresentaram maiores abundâncias foram Aechmea fasciata, Vriesea procera e Orchidaceae indet., que representam as famílias mais bem adaptadas ao epifitismo. Como já assinalado anteriormente, este é um resultado esperado para florestas com baixa pluviosidade (Gentry \& Dodson 1987).

A ausência de epífitas com baixa frequiência e alta abundância indica que epífitas de florestas secas não se encaixam no modelo de raridade de Rabinowitz et al. (1986) onde espécies raras podem ser abundantes localmente. Seria esperado que estas espécies fossem especialistas devido à melhor utilização de determinados recursos selecionados (Blüthgen et al. 2007). Assim, os resultados indicam que a hipótese sugerida por Callaway et al. (2002) de maior especialização epífita-hospedeiro em áreas mais secas pode não se aplicar apropriadamente a estes hábitats, devido a fatores ambientais (no caso umidade) restringirem a ocorrência da maioria das espécies às Bromeliaceae e Orchidaceae. Mesmo que a análise seja restrita a estas duas famílias, o poder de dispersão e estabelecimento de espécies sobre forófitos é grande, favorecendo a ocorrência destas famílias em diversas espécies arbóreas, como observado na floresta seca de Jacarepiá. No entanto, é possível que tal especificidade ocorra em áreas com menor riqueza arbórea do que a ocorrente na floresta seca (e.g., florestas subtropicais). Ainda assim, a ocorrência de epífitas estaria sendo restringida pelo número de espécies arbóreas ocorrentes na área e não por processos direcionados à ocorrência de epífitas nestas espécies arbóreas, o que caracterizaria uma especificidade real.

Os resultados de distribuição de bromélias e orquídeas por uma longa lista de forófitos e algumas abundâncias acima do padrão estabelecido de "alta abundância" sugerem que as epífitas possuam preferência por determinadas espécies arbóreas mas não especializações, como quantificado por Blüthgen et al. (2007). Estes autores analisaram as diversas especializações de redes de interações e verificaram que as simbioses obrigatórias mirmecofíticas representam as redes mais especializadas, seguidas das redes formadas por polinizadores e, por fim, das redes de dispersores, que são as menos especializadas. Os resultados de Jacarepiá sugerem que a rede formada por espécies epífitas e por hospedeiros deve possuir valores ainda mais baixos do que os atribuídos às redes de interações de dispersores.

As matrizes utilizadas sugerem que a interação comensalista de epífitas e forófitos formem uma rede aninhada (sensu Lewinshon et al.2006), como encontrado em outra comunidade de epífitas na Nova Zelândia (Burns 2007). Redes aninhadas resultam de diferenças na dispersão, na abundância ou na distribuição espacial das espécies envolvidas, porém sem uma base coevolutiva ou filogenética envolvendo a interação (Lewinshon et al. 2006). Uma das implicações em potencial do aninhamento e da assimetria das interações é que o padrão coeso representado pelo grupo central de espécies que interagem, pode promover rotas alternativas para respostas no sistema quando sob algum tipo de perturbação (Jordano 1987; Bascompte et al. 2003). Por exemplo, na perda de uma espécie de forófito, as epífitas teriam ainda outros forófitos para se manter. 


\section{Conclusões}

$\mathrm{Na}$ floresta seca de Jacarepiá, as espécies arbóreas mais abundantes é que hospedam mais epífitas. Quatorze espécies arbóreas foram especialmente propensas a ter muitos grupos epifíticos e nove foram propícias a ter várias espécies de epífitas, mas não em alta abundância. $\mathrm{O}$ número de indivíduos arbóreos foi um bom parâmetro para estimar o número de forófitos e a abundância de forófitos foi um bom parâmetro para estimar a abundância e riqueza de epífitas a ocorrerem nesta floresta seca. Quatro espécies arbóreas foram especialmente preferidas pelas duas espécies epífitas de maior abundância e freqüência na área, onde ocorreram com alta abundância. Entretanto, não houve seletividade de nenhuma espécie arbórea por epífitas raras ocorrentes na área.

\section{Agradecimentos}

O financiamento para a realização deste trabalho foi fornecido pela Coordenação de Aperfeiçoamento de Pessoal de Nível Superior (Capes) e o apoio de campo foi fornecido pelo Projeto Restinga (Instituto de Pesquisas Jardim Botânico do Rio de Janeiro). Agradecemos também ao auxílio prestado no campo por Jorge Caruso, Cecília Amorim de Freitas, Fernando Tatagiba, Gina Cardinott e Eduardo Amado. Agradecimentos especiais devem ser reconhecidos a Cyl Farney Catarino de Sá, Dorothy Sue Dunn de Araujo e Fábio Scarano que forneceram auxílio incomensurável para o início e desenvolvimento deste trabalho.

\section{REFERÊNCIAS BibLIOGRÁFICAS}

Alves, T. F. 2005. Distribuição geográfica, forófitos e espécies de bromélias epífitas nas matas e plantações de cacau da região de Una, Bahia. Tese de Doutorado. Universidade Estadual de Campinas, Campinas, 84p.

Bascompte, J.; Jordano, P.; Melián, C. J. \& Olesen, J. M. 2003. The nested assembly of plant-animal mutualistic networks. Proceedings of the National Academy of
Sciences of the United States of America 100: 9383-9387.

Begon, M.; Townsend, C. R. \& Harper, J. L. 2006. Ecology. From individuals to ecosystems. $4^{\text {th }}$ ed. Blackwell Publishing, Malden, 738p.

Bennet, B. C. 1987. Spatial distribution of Catopsis and Guzmania (Bromeliaceae) in southern Florida. Bulletin of the Torrey Botanical Club 114: 265-271.

Benzing, D. H. 1990. Vascular epiphytes. General biology and related biota. Cambridge Unversity Press, Cambridge, 376p.

Blüthgen, N.; Menzel, F.; Hovestadt, T.; Fiala, B. \& Blüthgen, N. 2007. Specialization, constraints, and conflicting interests in mutualistic networks. Current Biology 1: 341-346.

Borgo, M. \& Silva, S. M. 2003. Epífitos vasculares em fragmentos vasculares em floresta ombrófila mista, Curitiba, Paraná, Brasil. Revista Brasileira de Botânica 26: 391-401.

Breier, T. B. 1999. Florística e ecologia de epífitos vasculares em uma floresta costeira do sul do Brasil. Dissertação de Mestrado, Universidade Federal do Rio Grande do Sul, Porto Alegre, 83p.

Breier, T. B. 2005. O epifitismo vascular em florestas do Sudeste do Brasil. Tese de Doutorado. Universidade Estadual de Campinas, Campinas, 139p.

Bronstein, J. L. 1994. Our understanding of mutualism. The Quarterly Review of Biology 69: 31-51.

Burns, K. C. 2007. Network properties of an epiphyte metacommunity. Journal of Ecology 95: 1142-1151.

Callaway, R. M.; Reinhart, K. O.; Moore, G. W.; Moore, D. J. \& Pennings, S. C. 2002. Epiphyte host preferences and host traits: mechanisms for species-specific interactions. Oecologia 132: 221-230.

Cardelús, C. L.; Colwell, R. K. \& Watkins, J. E. 2006. Vascular epiphyte distribution patterns: explaining the mid-elevation richness peak. Journal of Ecology 94: 144-156. 
Carlsen, M. 2000. Structure and diversity of the vascular epiphyte community in the overstory of a tropical rain forest in Surumoni, Amazonas state, Venezuela. Selbyana 21: 7-10.

Cirne, P.; Zaluar, H. L. T. \& Scarano, F. R. 2003. Plant diversity, interspecific associations, and postfire resprouting on a sandy spit in a Brazilian coastal plain. Ecotropica 9: 33-38.

Cottam, G. \& Curtis, J. T. 1956. The use of distance measures in phytosociological sampling. Ecology 37: 451-460.

Cox, G. W. \& Ricklefs, R. E. 1977. Species diversity and ecological release in Caribbean land bird faunas. Oikos 28: 113-122.

Fontoura, T.; Sylvestre, L. S.; Vaz, A. M. S. F. \& Vieira, C. M. 1997. Epífitas vasculares, hemiepífitas e hemiparasitas da Reserva Ecológica de Macaé de Cima. In: Lima, H. C. \& Guedes-Bruni, R. R. (eds.). Serra de Macaé de Cima: diversidade florística e conservação em Mata Atlântica. Jardim Botânico do Rio de Janeiro, Rio de Janeiro. Pp. 89-101.

Galindo-González, J.; Guevara, S. \& Sosa, V. J. 2000. Bat- and bird-generated seed rains at isolated trees in pastures in a tropical rainforest. Conservation Biology 14: 1693-1703.

Gaston, K. J. 1994. Rarity. Chapman \& Hall, London.

Geßler, A.; Duarte, H. M.; Franco, A. C.; Lüttge. U.; Mattos, E. A.; Nahm, M.; Scarano, F. R.; Zaluar, H. L. T. \& Rennenberg, H. 2005. Ecophysiology of selected tree species in different plant communities at the periphery of the Atlantic Forest of SEBrazil II. Spatial and ontogenetic dynamics in Andira legalis, a deciduous legume tree. Trees 19: 510-522.

Gentry, A. \& Dodson, C. H. 1987. Diversity and biogeography of Neotropical vascular epiphytes. Annals of the Missouri Botanical Garden 74:205-233.

Gonçalves, C. N. \& Waechter, J. L. 2002. Epífitos vasculares sobre espécimes de
Ficus organensis isolados no norte da planície costeira do Rio Grande do Sul: padrões de abundância e distribuição. Acta Botanica Brasilica 16: 429-441.

Gonçalves, C. N. \& Waechter, J. L. 2003. Aspectos florísticos e ecológicos de epífitos vasculares sobre figueiras isoladas no norte da planície costeira do Rio Grande do Sul. Acta Botanica Brasilica 17: 89-100.

Greenberg, R. 1996. Managed forest patches and the diversity of birds in southern Mexico. In: Schelhas, J.; Greenberg, R. (eds.). Forest patches. Island Press, Washington D. C. Pp. 59-90.

Guimarães Jr., P. R.; Machado, G.; Aguiar M. A. M.; Jordano, P.; Bascompte, J.; Pinheiro A. \& Reis, S. F. 2007. Build-up mechanisms determining the topology of mutualistic networks. Journal of Theoretical Biology 249: 181-189.

Hietz, P. \& Hietz-Seifert, U. 1995. Structure and ecology of epiphyte communities of a cloud forest in central Veracruz, Mexico. Journal of Vegetation Science 6: 719-728.

Ingram, S. \& Nadkarni, N. M. 1993. Composition and distribution of epiphytic organic matter in a Neotropical cloud forest, Costa Rica. Biotropica 25: 370-383.

Jordano, P. 1987. Patterns of mutualistic interactions in pollination and seed dispersal: connectance, dependence asymmetries, and coevolution. The American Naturalist 129: 657-677.

Kersten, R. A. \& Silva, S. M. 2001. Composição florística e estrutura do componente epifítico vascular em floresta da planície litorânea na Ilha do Mel, Paraná, Brasil. Revista Brasileira de Botânica 24:231-226.

Kersten, R. A. \& Silva, S. M. 2002. Florística e estrutura do componente epifítico vascular em floresta ombrófila mista aluvial do rio Barigüi, Paraná, Brasil. Revista Brasileira de Botânica 25: 259-267.

Lewinsohn T. M.; Prado, P. I.; Jordano, P.; Bascompte, J. \& Olesen, J. M. 2006. Structure in plant animal interaction assemblages. Oikos 113: 174-184. 
Migenis, L. E. \& Ackerman, J. D. 1993. Orchid-phorophyte relationships in a forest watershed in Puerto Rico. Journal of Tropical Ecology 9: 231-240.

Mooney, K. A. 2007. Tritrophic effects of birds and ants on a canopy food web, tree growth, and phytochemistry. Ecology 88: 2005-2014.

Moran, R. C.; Klimas, S. \& Carlsen, M. 2003. Lowtrunk ferns on tree ferns versus angiosperms in Costa Rica. Biotropica 35: 48-56.

Olesen, J. M. \& Jordano, P. 2002. Geographic patterns in plant-pollinator mutualistic networks. Ecology 83: 2416-2424.

Perry, D. R. 1978. A method of access into the crowns of emergent and canopy trees. Biotropica 10: 155-157.

Rabinowitz, D.; Cairns, S. \& Dillon, T. 1986. Seven forms of rarity and their frequency in the flora of the British Isles. In: Soulé, M. E. (ed.). Conservation biology. The science of scarcity and diversity. Sinauer Associates, Sunderland. Pp. 182-204.

Richards, P. W. 1996. The tropical rain forest. $2^{\text {nd }}$ ed. Cambridge University Press, Cambridge, 600p.

Sá, C. F. C. 1992. A vegetaçäo da restinga de Ipitangas, Reserva Ecológica Estadual de Jacarepiá, Saquarema (RJ) fisionomia e listagem das angiospermas. Arquivos do Jardim Botânico Rio de Janeiro 31: 87-102.

Sá, C. F. C. 2002. Regeneração de um trecho de floresta de restinga na Reserva Ecológica
Estadual de Jacarepiá, Saquarema, estado do Rio de Janeiro: II - Estrato arbustivo Rodriguésia 53: 5-23.

Sá, C. F. C. \& Araújo, D. S. D. 2009 Estrutura de uma floresa de restinga em Ipitangas, Saquarem, RJ. Rodriguésia 60: 00-00.

Scudeller, V. V. 2002. Análise fitogeográfica da Mata Atlântica - Brasil. Tese de Doutorado. Universidade Estadual de Campinas, Campinas, 204p.

Stewart, A. J. A. 1996. Interspecific competition reinstated as an important force structuring insect herbivore communities. Trends in Ecology and Evolution 11: 233-234.

Ter Steege, H. \& Cornelissen, J. H. C. 1989. Distribution and ecology of vascular epiphytes in lowland rain forest of Guyana. Biotropica 21: 331-339.

Waechter, J. L.1980. Estudo fitossociológico das orquidáceas da mata paludosa do Faxinal, Torres, Rio Grande do Sul. Dissertação de Mestrado. Universidade Federal do Rio Grande do Sul, Porto Alegre, 104p.

Waechter, J. L. 1998. Epifitismo vascular em uma floresta de restinga do Brasil subtropical. Ciência \& Natura 20: 43-66.

Zotz, G. \& Vollrath, B. 2003. The epiphyte vegetation of the palm Socratea exorrhiza-correlations with tree size, tree age and briophyte cover. Journal of Tropical Ecology 19: 81-90. 